\title{
Characterization of sol-gel PZT films on Pt-coated substrates
}

\author{
J G E Gardeniers $\dagger$, A Smith $\dagger$ and C Cobianuł \\ $\uparrow$ Micromechanical Transducers, MESA Research Institute, PO Box 217, NL-7500 \\ AE Enschede, The Netherlands \\ $\ddagger$ Institute of Microtechnology, PO Box 38-160 Bucharest 72225, Romania
}

Received 14 December 1994, accepted for publication 4 January 1995

\begin{abstract}
A conventional sol-gel process was used to spin-cast PZT films on oxidized $\mathrm{Si}$ wafers coated with sputtered Pt layers. After annealing at $550^{\circ} \mathrm{C}-800^{\circ} \mathrm{C}$, the resulting perovskite-type PZT films showed different textures and surface morphologies, depending on whether or not a $\mathrm{Ti}$ adhesion layer was used. If a Ti layer was present, Ti diffusion into and through the Pt film leads to a compound $\mathrm{Pt}_{3} \mathrm{Ti}$, which facilitates crystallization of the perovskite PZT phase; without $\mathrm{Ti}$, crystallization is more difficult and occurs via the growth of dendritic crystallites. Several optical and electrical properties of the PZT films have been measured; the first results indicate high dielectric constants $(\epsilon \simeq 480)$ and acceptable ferroelectric behaviour.
\end{abstract}

\section{Introduction}

In recent years, interest in thin films of perovskitetype materials like $\mathrm{PbZr}_{x} \mathrm{Ti}_{1-x} \mathrm{O}_{3}$ (PZT) has increased considerably because of applications in e.g. ferroelectric non-volatile memory devices and piezoelectrically driven microelectromechanical systems. An important topic of investigation is the choice of the electrode materials to be included in the conventional electrode-PZT-electrode sandwich design used in these applications. The choice of the electrode material is dominated by two aspects: (i) reactivity, and (ii) enhancement of oriented crystallization. Because of the high temperatures required during deposition or annealing of PZT, a chemically inert electrode material like platinum would be preferred to prevent reactions between constituents of the layer package. However, the results obtained with this and other metals are inconsistent, especially with respect to ferroelectric fatigue. For this reason several authors have tried conducting oxides, like $\mathrm{La}_{0.05} \mathrm{Sr}_{0.5} \mathrm{CoO}_{3}[1,2]$. Metals are still preferred in most applications, however, because of their much lower resistivities.

In this paper we shall discuss some of our results obtained with $\mathrm{Pt}$ electrodes. Because the adhesion of $\mathrm{Pt}$ layers on substrates like $\mathrm{Si}-\mathrm{SiO}_{2}$ or $\mathrm{Si}-\mathrm{Si}_{3} \mathrm{~N}_{4}$ is insufficient, an adhesion layer is generally required. Several metals can be used for this purpose, although $\mathrm{Ti}$ is the most popular. In this paper we shall extend our earlier work [3], which was focused on the structural implications of the use of a $\mathrm{Ti}$ adhesion layer, and present additional electrical and optical measurements on sol-gel PZT films on Pt-Ti coated substrates.

\section{Experimental procedure}

A conventional sol-gel process [4] (solution composition: $\mathrm{Pb}: \mathrm{Zr}: \mathrm{Ti}=1.05: 0.53: 0.47$ ) was used to spin-cast films on 3 inch $\mathrm{Si}$ substrates coated with thermal $\mathrm{SiO}_{2}$, LPCVD $\mathrm{Si}_{3} \mathrm{~N}_{4}$, DC-magnetron sputtered $\mathrm{Pt}, \mathrm{Ti}, \mathrm{Cr}$, or combinations of these layers. The gel films were dried in air $(20 \mathrm{~min}$, $120^{\circ} \mathrm{C}$ ) and subsequently annealed in an oven in a pure $\mathrm{O}_{2}$ flow, at temperatures between $400^{\circ} \mathrm{C}$ and $850^{\circ} \mathrm{C}$; several different heating treatments were tried. One spinning plus annealing cycle leads to a PZT film with a thickness of around $60 \mathrm{~nm}$; for thicker films multiple cycles were used. The PZT films were characterized with $x$-ray diffraction (XRD) with a $\mathrm{Cu}$ source, energy dispersive $\mathrm{X}$ ray spectroscopy (EDX), Auger electron spectroscopy (AES), and ellipsometry (wavelengths: $632.8 \mathrm{~nm}$ and $1500 \mathrm{~nm}$ ); dielectric constants and ferroelectric hysteresis loops of the films were measured on $1 \mathrm{~mm}^{2}$ capacitors, using a network analyzer and a conventional Sawyer-Tower setup, respectively.

\section{Results and discussion}

Figure 1 shows ellipsometer results $(632.8 \mathrm{~nm})$ for PZT layers on different substrates, resulting from a single spincasting step, which after drying at $120^{\circ} \mathrm{C}$ were annealed at subsequent temperatures of 400 up to $850^{\circ} \mathrm{C}$. Several effects can be observed: (i) the layers deposited on Pt(Ti) continuously shrink during annealing, up to a factor of 3 , while the refractive index increases up to $700^{\circ} \mathrm{C}$, and decreases slightly for still higher temperatures; the latter effect is probably due to $\mathrm{Pb}$ loss, as could be confirmed by EDX measurements; 

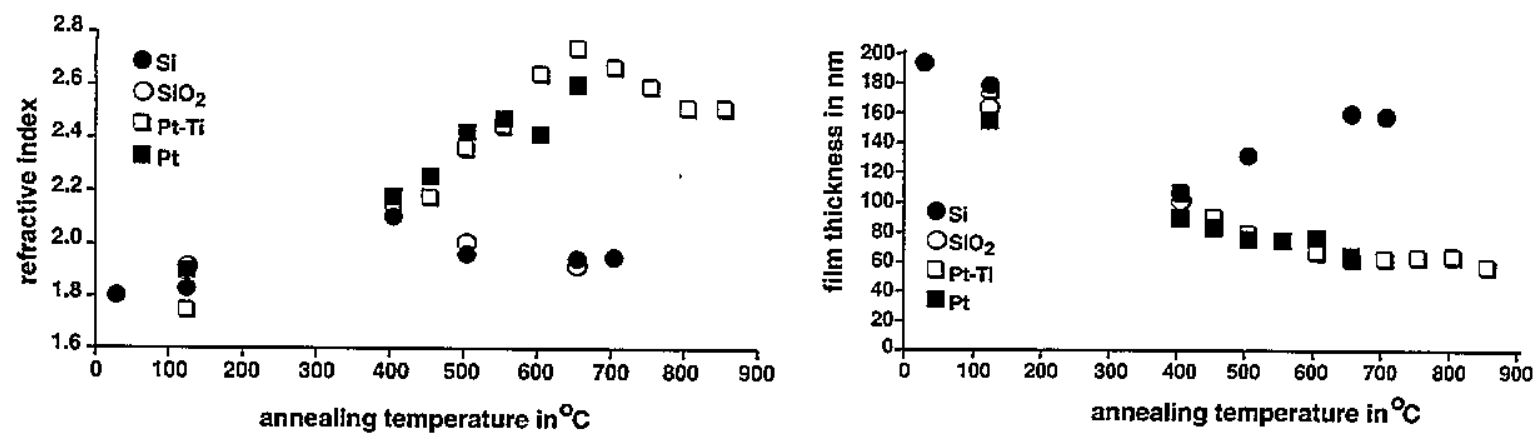

Figure 1. Annealing results of $\mathrm{PZT}$ on $\mathrm{Si}, \mathrm{SiO}_{2}-\mathrm{Si}, \mathrm{Pt}-\mathrm{SiO}_{2}-\mathrm{Si}$ and $\mathrm{Pt}-\mathrm{Ti}-\mathrm{SiO}_{2}-\mathrm{Si}$.
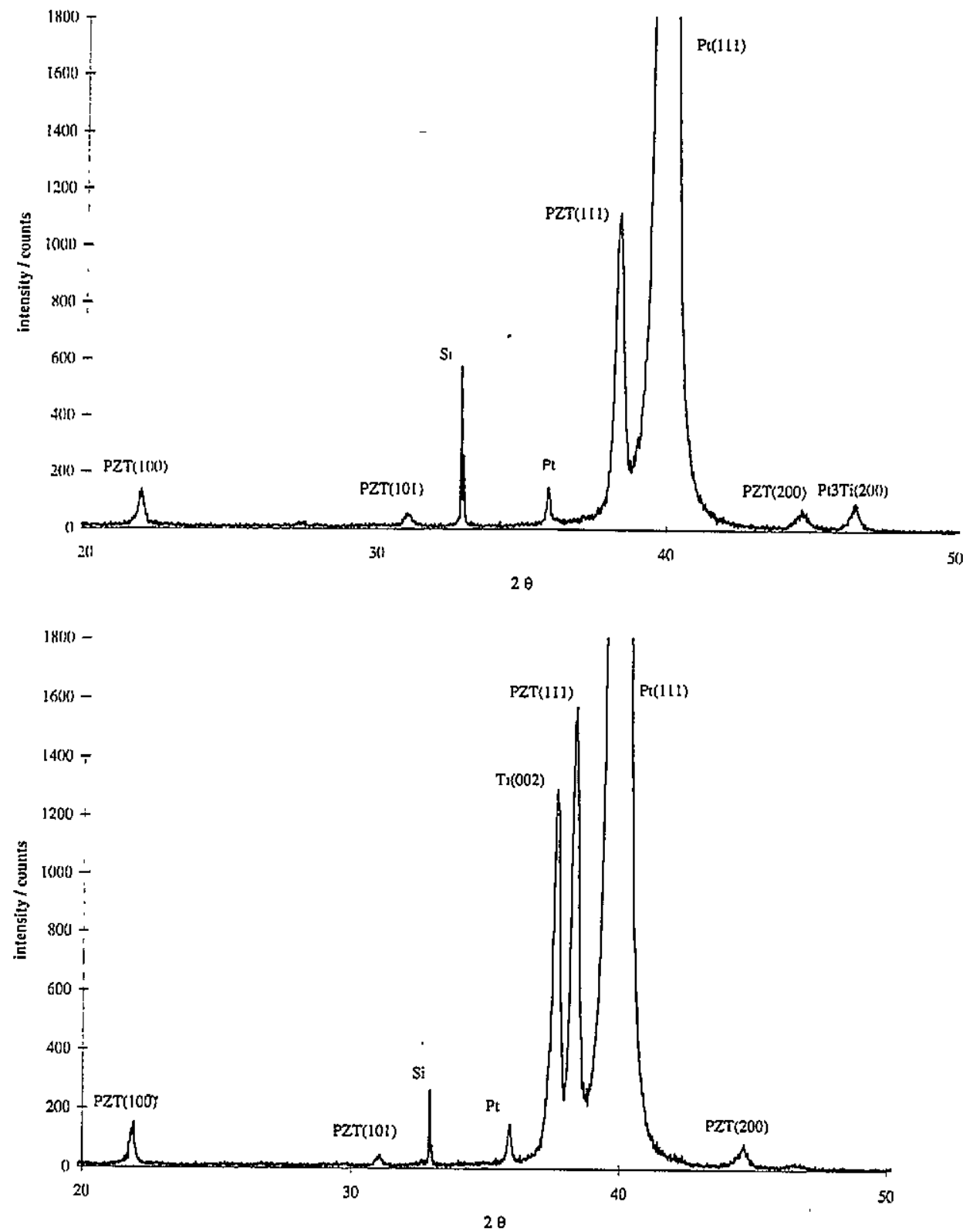

Figure 2. XRD spectra of PZT on Pt-Ti-SiO ${ }_{2}-\mathrm{Si}$; M8P (top) and MiN (bottom); see text.

(ii) the layers on $\mathrm{Si}$ and $\mathrm{SiO}_{2}$ (and also on $\mathrm{Si}_{3} \mathrm{~N}_{4}$, although not shown in the figure) shrink up to around $400^{\circ} \mathrm{C}$, and become thicker again for higher temperatures; the refractive index increases up to, and decreases above $400^{\circ} \mathrm{C}$; these effects are the result of a reaction of the PZT film with $\mathrm{Si}$; this reaction prevents the crystallization of the perovskite PZT phase, as could be concluded from XRD measurements. The reaction also leads to cracks in the films, which do not occur in the films on Pt.

XRD results indicate that the structure of the PZT 

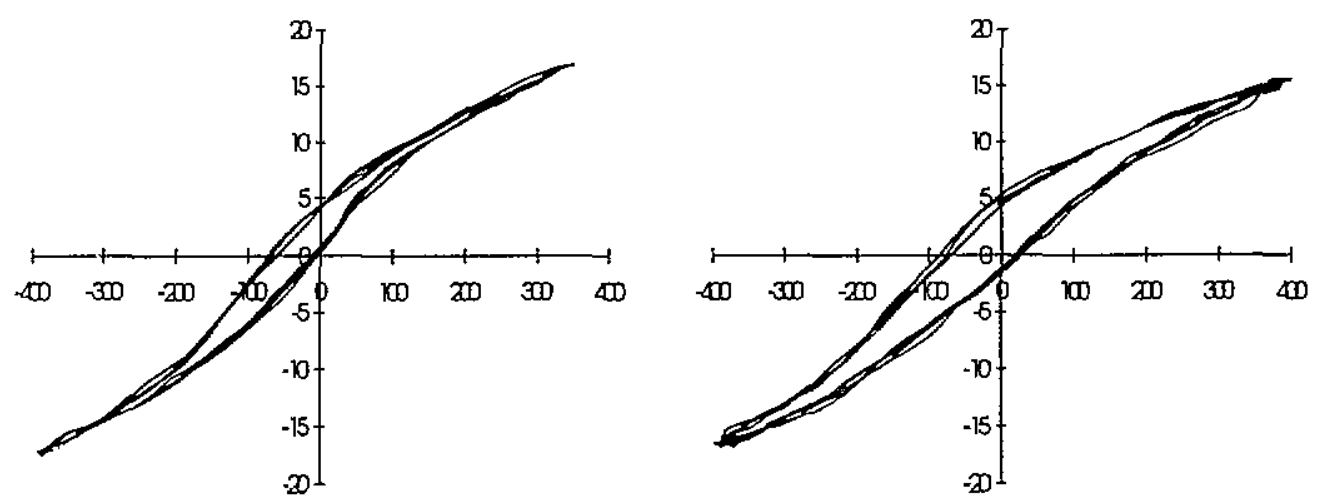

Figure 3. Ferroelectric hysteresis loops at $1 \mathrm{kHz}$ for samples M8P (left) and M1N (right). Horizontal axis: electric field in $\mathrm{kV} \mathrm{cm}-1$, vertical axis: polarization in $\mu \mathrm{C} \mathrm{cm}^{-2}$.

films on $\mathrm{Pt}$ (with or without $\mathrm{Ti}$ ) is nanocrystalline pyrochlore for annealing temperatures up to around $500^{\circ} \mathrm{C}$; at that temperature faint perovskite-type PZT diffractions are observed, which become more intense at higher temperatures. The refractive index values in figure 1 agree with this trend in crystal structure development, considering reported values of 1.65 for pyrochlore and around 2.6 for sol-gel deposited perovskite PZT [5].

Figure 2 shows XRD spectra of around $200 \mathrm{~nm}$ thick, PZT films on Pt-Ti, resulting from 3 subsequent spin-casting $c q$ annealing steps. Two different cycles were used: for sample M8P the process sequence was: spinning $-20 \mathrm{~min}$ at $120^{\circ} \mathrm{C}, 10 \mathrm{~min}$ at $700^{\circ} \mathrm{C}$, spinning, etc., while for M1N it was spinning-20 min at $120^{\circ} \mathrm{C}, 20 \mathrm{~min}$ at $300^{\circ} \mathrm{C}, 1 \mathrm{~min}$ at $700^{\circ} \mathrm{C}$, and again spinning. A lift-off process was used to deposit $\mathrm{Al}$ electrode patterns on top of the PZT layer. The only remarkable difference in the two XRD spectra is the presence of the $\alpha$-Ti (002) peak at $38.22^{\circ}$ for sample MiN, which for sample M8P is replaced by a small peak at $46.50^{\circ}$. The latter peak is due to $\mathrm{Pt}_{3} \mathrm{Ti}\{200\}$ [3], which compound is the result of the diffusion of $\mathrm{Ti}$ into the $\mathrm{Pt}$ layer (as confirmed by AES measurements).

XRD measurements [3] show that PZT on Pt without Ti has a strong (101)/(011) texture, while in the presence of Ti the PZT layer has crystals with $(100) /(010)$ or (111) faces parallel to the surface, as shown in figure 2; the relative occurence of the latter crystals varies from sample to sample, but a trend seems to be that more $(100) /(011)$ is found on samples which were subjected to a higher thermal budget. One could argue that the Ti which diffuses through the Pt film precipitates close to the Pt surface (as indeed observed in AES) in a $\mathrm{Pt}_{3} \mathrm{Ti}$ phase with (200) texture, on which PZT (100) grows epitaxially; similarly, as suggested by others [6], PZT (111) could grow epitaxially on Pt (111). The latter is however not in agreement with the texture observed for PZT on $\mathrm{Pt}$ without Ti.

Figure 3 shows ferro-electric hysteresis loops for the two samples on Pt-Ti. The sample obtained with the lowest thermal budget (M1N) shows a somewhat better loop. It might be that this is a result of less Ti diffusion through the Pt film, although it is not clear what the effect of a Ti-rich interface on ferro-electric behaviour would be.

The dielectric constants of film M8P varied from 435 at the wafer edge to 510 at the wafer center. This variation is not caused by thickness non-uniformity, which is only $2 \%$, but is probably due to a higher loss of $\mathrm{Pb}$ from the film at the wafer edges.

It would be interesting to compare the electrical properties of PZT films on $\mathrm{Pt}$ with and without $\mathrm{Ti}$ underneath. However, first attempts to do this failed because of a strongly decreased adhesion of the $\mathrm{Pt}$ film on $\mathrm{SiO}_{2}$-coated $\mathrm{Si}$ after annealing, which resulted in blisters which penetrated through the PZT film and gave rise to electrical shorts between $\mathrm{Al}$ top and $\mathrm{Pt}$ bottom electrodes. Other adhesion layers for the $\mathrm{Pt}$ electrode are currently being tested.

\section{Acknowledgments}

The authors thank B Otter for EDX and A van den Berg for AES measurements, and $J$ Sanderink for sputtering depositions.

\section{References}

[1] Ramesh B, Lee J, Sands T. Keramidas V G and Auciello O 1994 Appl. Phys. Lett. 642511

[2] Dat R, Lichtenwalner D J, Auciello O and Kingon A I 1994 Appl Phys. Lett. 642673

[3] Gardeniers J G E. Elwenșpoek M and Cobianu C 1994 Texture variations in sol-gel derived PZT films on substrates with platinum metallization MRS Symp. Proc. 343 p 451

[4] Udayakumar K R, Chen J, Krupanidhi S B and Cross L E 1990 Proc. 7th Int. Symp. Appl. Ferroel. (Urbana-Champaign) p 741

[5] Uhlmann D R, Teowee G, Boulton J M, Mokatef S and Lee S C 1992 J. Non-Cryst. Solids 147-148 409

[6] Tani T, Xu $Z$ and Payne D A 1993 Ferroelectric Thin Films III, MRS Symp. Proc. 310269 